\title{
Nos caminhos da transparência pública de uma Instituição Federal de Ensino: uma experiência extensionista
}

\author{
On the paths of public transparency in a Federal Education Institution: an extension \\ experience
}

\author{
Wandilson Alisson Silva Lima ${ }^{1}$ \\ Anne Karynne Guimarães Ramos ${ }^{2}$
}

\section{RESUMO}

A transparência pública é considerada um dispositivo da gestão fiscal responsável, ligado ao princípio constitucional da publicidade. Enquanto cidadãos, temos o direito e o dever de fiscalizar a aplicação das receitas oriundas de diversas fontes, por intermédio da exposição de ações públicas. De tal modo, este relato de experiência tem como objetivo descrever os resultados de um projeto de extensão que buscou promover a transparência do IF Sertão PE Campus Santa Maria da Boa Vista, demonstrando a importância e as principais informações institucionais para o público-alvo. A metodologia do projeto se deu em quatro etapas: preparação, divulgação, realização e avaliação, que foram executadas em 4 escolas públicas com aproximadamente 250 estudantes, em 2017. Em suma, as ações do projeto foram consideradas relevantes, os alunos revelaram que não conheciam o Instituto Federal, nem possuíam o hábito de acessas as informações públicas pelo portal. Realizaram-se visitas técnicas ao Campus a fim de incentivar uma maior aproximação entre Instituto e comunidade. Além de cumprir com aspecto legal, as visitas nas escolas e no Instituto foram caminhos viáveis à troca de saberes e conhecimentos quanto à transparência pública sobre temas relacionados ao contexto histórico, ensino, assistência estudantil, pesquisa, inovação, extensão, cultura e orçamento institucional, proporcionando também o controle social.

Palavras-chave: Controle social. Instituto Federal. Projeto de extensão. Transparência pública.

\begin{abstract}
Public transparency is considered to be a liability mechanism for tax management, linked to the constitutional principle of publicity. As citizens, we have the right and the duty to oversee the application of revenues from different sources, through the exposure of public actions. In such a way, the experience report describes the results of the experiences of an extension project that sought to promote the transparency of the Federal Institution in Sertão PE: Campus Santa Maria da Boa Vista, demonstrating the importance and the main institutional information for the target audience. The project methodology was followed in four stages, preparation, dissemination, realization and evaluation, in which they were carried out in 4 public schools with approximately 250 students, in 2017. In addition, as the project was considered relevant, some will reveal that it is not consistent with the Federal Institute, neither had not even a habit of accessing social information through the portal. Technical visits were also made to the Campus, in order to encourage a closer approach between the Institute and the community. In addition to complying

\footnotetext{
${ }^{1}$ Doutorando em Administração na Universidade Federal da Bahia, Brasil; administrador do Instituto Federal de Educação, Ciência e Tecnologia do Sertão Pernambucano, Campus Petrolina, Brasil (wandilson900@live.com).

2 Técnica em Edificações pelo Instituto Federal do Sertão Pernambucano, Campus Petrolina, Brasil. (anne_karynne@ hotmail.com).
} 
with the legal aspect, such as visits to schools and the Institute, viable ways were the exchange of knowledge and knowledge regarding public transparency on issues related to the historical context, teaching, student assistance, research, innovation, extension, culture and budget institutional, also providing social control.

Keywords: Social control. Federal Institute. Extension project. Public transparency.

\section{INTRODUÇÃO}

Atualmente, há alguns mecanismos legais de controle social, por meio do portal da transparência pública, ouvidorias, auditorias internas, procuradorias, Constituição Federal de 1988, Lei de Responsabilidade Fiscal (LRF) e Lei da Transparência (Lei Complementar nº 131/2009). Mais recentemente, a promulgação da Lei de nº 12.527/2011, denominada de Lei Acesso à Informação (LAI), que regula o acesso às informações públicas enquanto direito constitucional (BRASIL, 2011). Esses dispositivos nos permitem obter diversas informações públicas dos recursos financeiros, licitações, contratos, diárias e passagens, servidores públicos e outros. Enquanto cidadãos, temos o direito e o dever de fiscalizar a aplicação das receitas oriundas de diversas fontes da "coisa" pública.

A transparência e a participação popular foram expandidas principalmente pela LRF, a legalidade trouxe uma série de obrigações para a administração pública no que se refere a prestar contas ao cidadão e à sociedade (CASTRO, 2013). O controle social é imprescindível para a sociedade, já que a população, por meio dos mecanismos de transparência pública e do exercício da cidadania ativa, pode solicitar do Estado informações e respostas (ações) eficientes às demandas públicas. Ainda assim, os órgãos devem apresentar suas prestações de contas independentemente de solicitação em seus sítios eletrônicos, de maneira responsiva, com vistas a cumprir o princípio da publicidade e as leis vigentes (PINHO; SACRAMENTO, 2009; FERNANDES; FERNANDES; TEIXEIRA, 2018).

Para Viccari Jr. et al. (2009) e Cruz et al. (2012), publicidade e transparência não se confundem, pois a transparência engloba, além da disponibilização dos números e atos da gestão, próprios da publicidade, há a necessidade que essas informações estejam em condição de interpretação pela população em geral. Isto é, a informação deve ser relevante, confiável, tempestiva e compreensível. Assim, o modo como o conteúdo é divulgado influencia diretamente na existência da transparência. Atualmente, há algumas formas de controle por entidades que buscam avaliar o desempenho da gestão pública como, por exemplo, o Tribunal de Contas da União (TCU) e Controladoria Geral da União (CGU). 
Desse ponto de partida, desenvolveu-se um projeto extensionista intitulado "IF Sertão Campus Santa Maria da Boa Vista de portões abertos: nos caminhos da transparência" a fim de demonstrar práticas de transparência pública no contexto do Instituto e proporcionar o diálogo com a sociedade em geral. Então, para além de cumprir um mecanismo legal, os espaços públicos (como escolas, por exemplo) podem ser caminhos viáveis à troca de saberes e conhecimentos, inclusive proporcionando a transparência pública aos cidadãos por intermédio da extensão universitária. Quando se pretende expor relatos de experiência de projeto de extensão, Bartillotti et al. (2015) ratificam a relevância quanto ao engajamento na busca por direitos e promoção da política, com ênfase na demonstração de dados governamentais como mecanismo de aprimoramento do controle social.

A principal inquietação e motivação de desenvolver o projeto foi refletir como o IF Sertão PE pode contribuir para implementar boas práticas de transparência pública diante de sua comunidade. Esse relato de experiência tem o objetivo geral de descrever os resultados das experiências de um projeto de extensão que buscou promover a transparência do IF Sertão PE Campus Santa Maria da Boa Vista, demonstrando a importância e as principais informações institucionais para o público-alvo. Isto posto, pretende-se aproximar a Instituição de seus principais atores sociais, além de cumprir com o papel social de transparência pública, divulgação da estrutura administrativa, recursos financeiros e orçamentários, programas, ações, projetos e obras diante de sua atuação central em ensino, pesquisa e extensão.

Diante do exposto, ressalta-se o papel do IF como agente de transformação social pode proporcionar a apresentação do Campus Santa Maria da Boa Vista para seu principal públicoalvo que são estudantes egressos do ensino fundamental e médio. De tal modo, o projeto pretende "abrir os portões" da instituição para comunidade em dois momentos distintos e complementares. O primeiro, com a ida até as escolas públicas; e o segundo, com a visita técnicas dos estudantes dessas escolas ao Instituto. Essa ação extensionista também visa, longo prazo, que os atores sociais se sintam pertencidos ao IF Sertão PE e compreendam sua atuação enquanto agentes de transformação social.

Além dessa introdução, o trabalho destaca os aspectos metodológicos que contextualizaram o local das ações de extensão e a estrutura das etapas das oficinas. Em seguida, apresentamos resultados e discussão a partir da execução do projeto. E, por fim, as considerações finais que trazem os aspectos conclusivos. 


\section{ASPECTOS METODOLÓGICOS}

O município de Santa Maria da Boa Vista, localizada no estado de Pernambuco, com a população de 41.931 habitantes (estimativa 2019) (IBGE, 2019), situa-se na bacia do Rio São Francisco e do Rio Pontal. Distante $611 \mathrm{~km}$ da Capital Recife, faz parte da Região Administrativa Integrada de Desenvolvimento do Polo Petrolina e Juazeiro. No portal do IF Sertão PE informa que, além de Santa Maria da Boa Vista, o Campus se estende aos municípios de Lagoa Grande, Orocó e Cabrobó (IF SERTÃO PE, 2019).

A população-alvo do projeto foram os alunos das séries finais do ensino fundamental $\left(9^{\circ}\right.$ ano) e médio ( $3^{\circ}$ ano) da rede pública municipal e estadual de Santa Maria da Boa Vista, além dos professores e diretores dessa rede que acompanharam as ações. Outros atores sociais (complementares) foram relevantes na consecução das ações, a saber: técnicos-administrativos, docentes, alunos bolsistas e voluntários do Instituto Federal. A meta estipulada inicialmente foi de 4 escolas e 200 estudantes, em 2017. O projeto foi concebido através de quatro etapas, a saber: preparação, divulgação, realização e avaliação.

Na etapa 1, a preparação do projeto envolveu a estruturação das principais informações que o IF SERTÃO PE Campus Santa Maria da Boa Vista. Para isso, fez-se necessário considerar o cumprimento previsto em Lei $\mathrm{n}^{\circ}$ 12.527/2011 no seu Art. 8 “é dever... promover, independentemente de requerimentos, a divulgação em local de fácil acesso [...] de informações de interesse coletivo" (BRASIL, 2011). Este dispositivo é um aparato legal que reforça a imprescindibilidade de transparência pública das informações à comunidade, sem necessariamente haver solicitação explicita. Por isso, a execução do projeto possui relevância para além do cumprimento de aspectos legais.

Assim, ainda nessa primeira etapa, foram levantadas e sistematizadas as seguintes informações: estrutura administrativa, recursos financeiros e orçamentários, programas, ações, projetos e obras. Concentrou-se primordialmente no princípio de indissociabilidade entre ensino, pesquisa e extensão. No campo do ensino, os principais cursos, formas de entradas, número de vagas, estatísticas de ingressantes e concluintes. Na linha de pesquisa e inovação, os programas, bolsas e projetos executados e previstos. Na área da extensão, os programas, bolsas e projetos, além dos impactos sociais nos espaços. 
Na etapa 2, foi definida a agenda com as escolas participantes, e a divulgação realizada em sala de aula, murais, redes sociais, e-mails e outros. Durante a etapa 3, o projeto foi executado por meio de cinco eixos por meio de oficinas estruturadas (Quadro 1):

Quadro 1 - Eixos temáticos e assuntos abordados

\begin{tabular}{|l|l|}
\hline \multicolumn{1}{|c|}{ Eixos: Temáticas abordadas } & \multicolumn{1}{c|}{ Assuntos Específicos } \\
\hline Histórias e Contextos & - Breve histórico \\
& - Estrutura Administrativa \\
& - Planejamento Institucional \\
\hline Ensino e Assistência Estudantil & - Formas de Ingresso \\
& - Estatísticas: vagas, matrículas, trancamentos e outros \\
& - Programação: bolsas, auxílios e informações relevantes \\
\hline Pesquisa e Inovação & - Prestação de contas \\
& - Planejamento: quantidade de bolsas, principais \\
& programas e projetos \\
\hline Extensão e Cultura & - Prestação de contas \\
& - Planejamento: quantidade de bolsas, principais \\
& programas e projetos \\
\hline Orçamento Público & - Histórico orçamentário do campus: realizado x previsto \\
\hline
\end{tabular}

Fonte: Os autores (2019).

As informações buscaram objetividade, clareza e direcionamento, bem como metodologias e linguagens que promovessem o entendimento e o diálogo com o público-alvo. Partindo dos pressupostos supracitados, o projeto foi realizado na própria escola dos alunos (público-alvo) atendidos pelo projeto a fim de proporcionar a exposição das informações por meio dos equipamentos de multimídia.

Foram realizadas também visitas técnicas às instalações do Campus Santa Maria da Boa Vista para incentivar uma maior aproximação entre Instituto e comunidade. Além do mais, estimular a convivência e a experiência com o espaço social, buscando impulsionar a procura por essa instituição.

A Etapa 4 se concentrou na avaliação, nela foram aplicados os questionários aos alunos da rede municipal e estadual no término da apresentação, objetivando saber o grau de percepção, a importância, as críticas, elogios e principais impactos após a realização do projeto. Os 
estudantes responderam a 198 questionários voluntariamente, esclarecendo finalidade e garantindo anonimato.

A redação do presente relato de experiência extensionista ocorreu após a consecução das etapas do projeto, compilação dos dados e redação dos resultados e discussões.

\section{RESULTADOS E DISCUSSÃO}

De modo geral, as ações extensionistas foram avaliadas como positivas pelos atores sociais envolvidos: gestor escolar, professor e estudantes das escolas, equipe do projeto (coordenador, colaboradora, bolsista e voluntários). A preparação antes de ir a campo foi crucial para execução das ações, uma vez que as informações foram coletadas, estruturadas e realizadas dentro dos eixos propostos, a saber: histórico, ensino, pesquisa, extensão, inovação, assistência estudantil e orçamento.

A importância de abordar o orçamento público em projeto de extensão é defendida por Miranda Júnior, Permínio e Leitão (2012), que justificam a aproximação da sociedade com os dados orçamentários, desmistificando as dificuldades quanto ao tema pela comunidade. Faz-se necessário divulgar as informações das organizações públicas, sem que haja necessariamente uma demanda explicita da comunidade a fim de demonstrar o comprometimento institucional com a transparência.

As principais informações demonstradas foram sobre o contexto histórico, estrutura administrativa, instalações e infraestrutura, ensino (formas de ingresso e cursos), assistência estudantil, pesquisa e inovação, extensão e cultura, recursos financeiros e orçamentários, programas, ações, projetos e obras.

Primeiramente, versou-se sobre a expansão da Rede Federal de Educação Técnica e Profissional que contemplou o Campus Santa Maria da Boa Vista do IF Sertão-PE, e foi anunciada em agosto de 2011. O lançamento da pedra fundamental da unidade, que está sendo erguido na BR 428, Km 94, zona rural do município, foi realizado em 10/02/2014. Assim, as atividades administrativas do Campus foram iniciadas em agosto de 2014, com sua missão que consiste no ensino, na pesquisa e na extensão, abrangendo também os municípios de Orocó, Lagoa Grande e Cabrobó. 
A infraestrutura física do Campus provisório possui salas de aulas, Secretaria Acadêmica, Coordenação Pedagógica (Docentes), Administração e Planejamento, Direção Geral do Campus e Setor de Saúde. Com o quantitativo de servidores totalizando 59 entre técnicos administrativos e docentes.

O foco das ações extensionistas do projeto residiu na transparência pública à luz da transparência pública, com informações gerais da instituição, bem como a prestação de contas, com o intuito de promover o controle social, e proporcionar o diálogo transversal com a comunidade (Figura $1)$.

Figura 1 - Registros fotográficos de algumas oficinas realizadas nas escolas

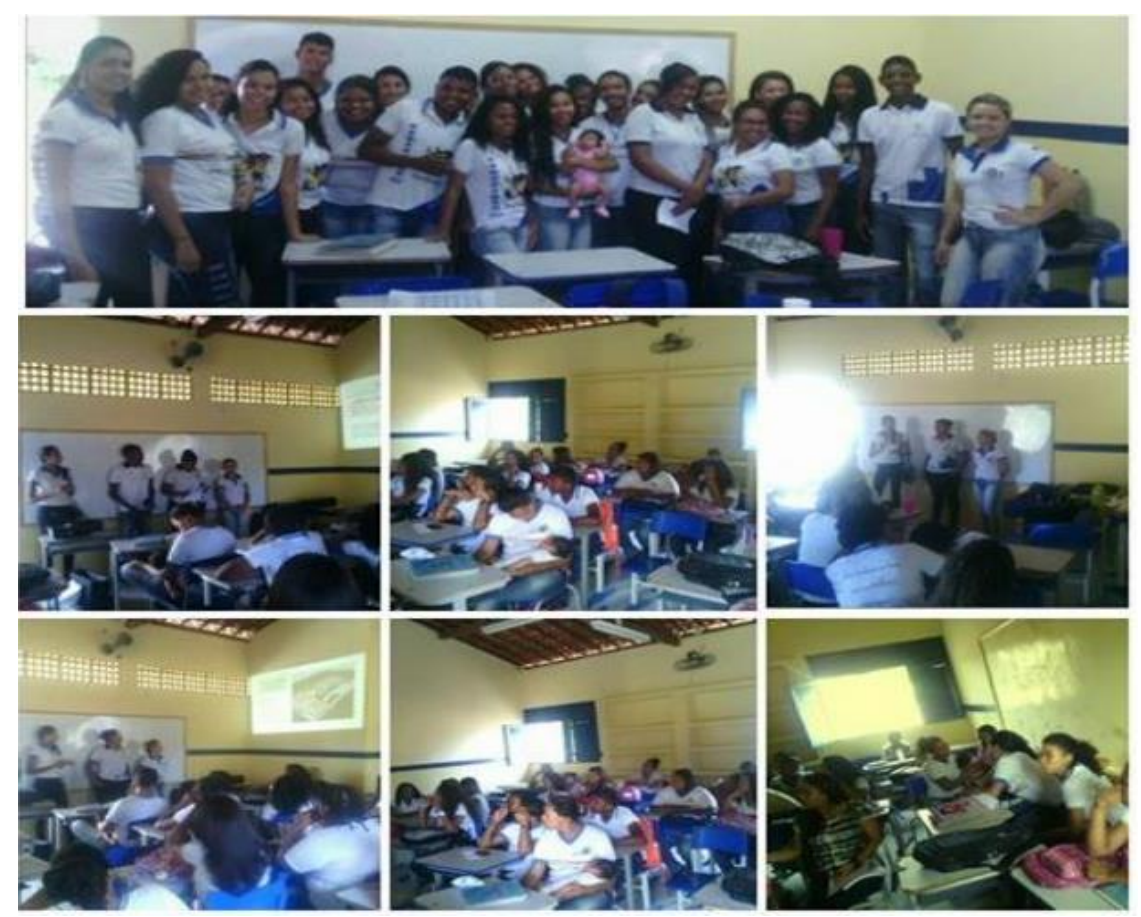

Fonte: Os autores (2018).

Os registros fotográficos a seguir demonstram a execução do projeto em outras escolas da rede pública (Figura 2), um momento aguardado, já que o Campus é a única Instituição Federal de ensino no Município de Santa Maria da Boa Vista. Nessa cidade, o Instituto oferece cursos regulares nas modalidades Subsequente (Agropecuária e Edificações), Médio Integrado ao subsequente, Programa Nacional de Integração da Educação Profissional - Proeja (Auxiliar em Agropecuária), além de Cursos de Formação Inicial e Continuada (FIC). Com planejamento para implementação de nível superior, dos cursos de Tecnólogo em Alimentos e Agronomia. 
Figura 2 - Registros fotográficos de algumas oficinas realizadas nas escolas

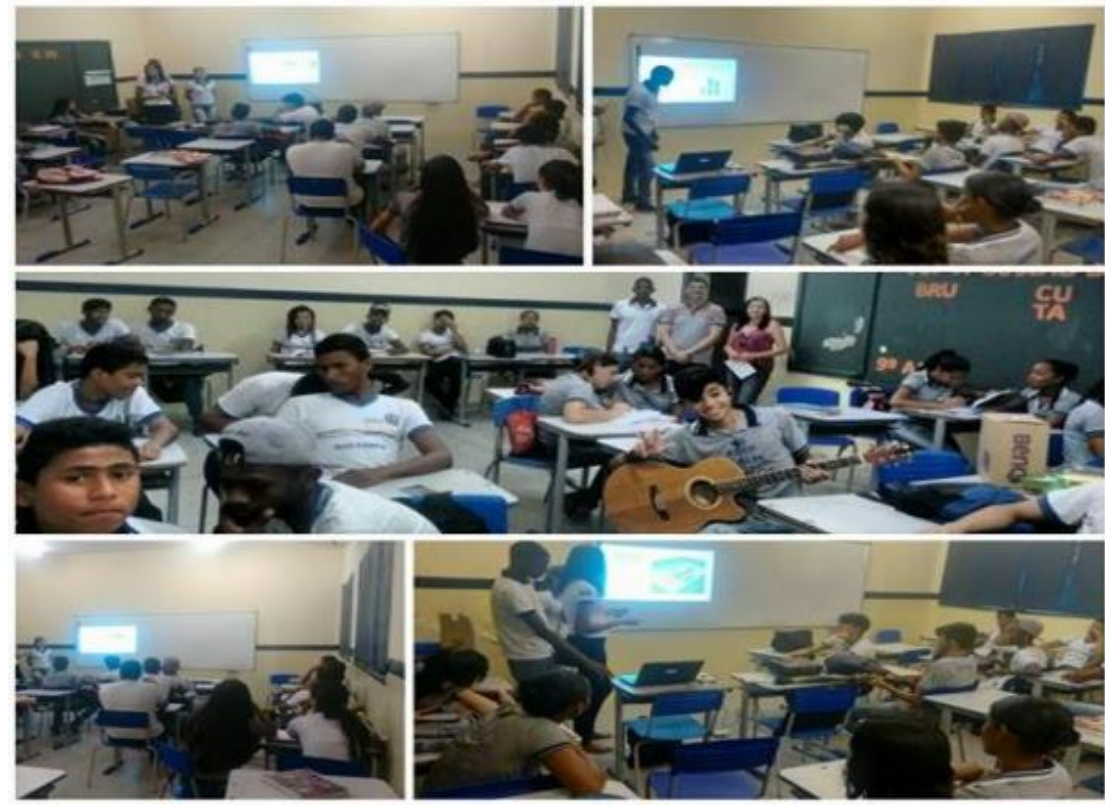

Fonte: Os autores (2018)

O Programa de Assistência Estudantil do IF Sertão-PE foi demonstrado, explicitando o conjunto de ações implementadas que objetiva favorecer e criar condições de acesso e permanência aos estudantes em situação de vulnerabilidade socioeconômica, por meio da concessão de auxílios (moradia, alimentação e transporte) regulamentados pela Portaria Normativa $n^{\circ}$ 2/2012 do Conselho Superior em consonância com o Decreto $n^{\circ}$ 7.234/ 2010 Programa Nacional de Assistência Estudantil (PNAES).

Em relação à pesquisa e inovação, foi explicitado que o Campus desenvolve pesquisa por intermédio dos seguintes programas institucionais: Programa Institucional de Bolsas de Iniciação Científica (Pibic), que oferta bolsas para execução de projetos no valor de R\$ 200,00 por mês, através de edital para alunos do nível médio (Modalidade Pibic Jr.), com 5 projetos em desenvolvimento; e o Programa Institucional de Bolsas de Iniciação em Desenvolvimento Tecnológico e Inovação (Pibiti), ofertado anualmente através de edital para alunos, com um projeto em desenvolvimento.

No que se refere ao setor de extensão, responsável pelo acompanhamento e desenvolvimento de ações que relacionam o Campus SMBV à comunidade local, são desenvolvidas algumas atividades extensionistas e de cultura. Na esfera do estágio, é realizado atendimento a alunos, recebimento de formulários e relatórios, atendimento a empresas parceiras do IF Sertão PE, além disso, a confecção de acordos de cooperação com empresas privadas e órgãos públicos, 
A seção de visitas técnicas, responsável pelo gerenciamento e controle de visitas técnicas no Campus SMBV, executa-se desde o agendamento ao arquivamento de todas as solicitações de visitas com alunos. Há o Programa Institucional de Bolsas de extensão (PIBEX) composto por seis projetos com bolsas no valor de $\mathrm{R} \$ 200,00$ por mês.

Foi detalhado o histórico do orçamento do Campus Santa Maria da Boa Vista durantes os anos de 2015 a 2017, conforme figura a seguir:

Figura 3 - Histórico do orçamento do Campus Santa Maria da Boa Vista (2015-2017)

Histórico do Orçamento do Campus Santa $\mathrm{M}^{\mathrm{a}}$ da Boa Vista

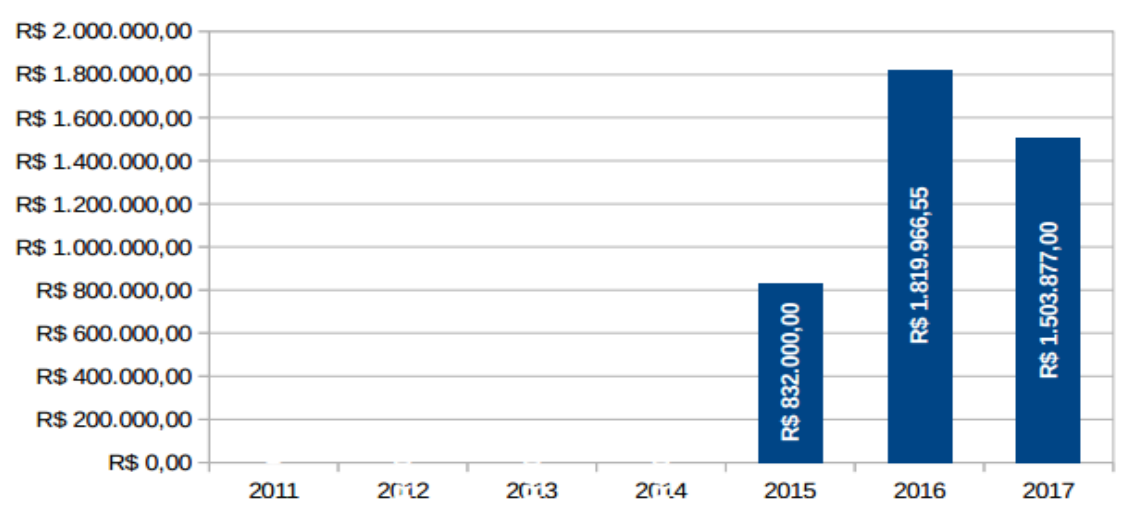

Fonte: Dados institucionais (2018).

Com o objetivo de verificar a atuação das ações extensionistas, aplicávamos questionários ao final de cada oficina, com total de 198 respostas. Em relação ao conhecimento sobre a página do IF Sertão PE, observamos desconhecimento por maioria dos entrevistados (Gráfico 1), o que nos leva a entender que o nosso projeto contribuiu de forma eficaz para a divulgação da Instituição.

Gráfico 1 - Frequência de acesso ao portal do IF Sertão-PE

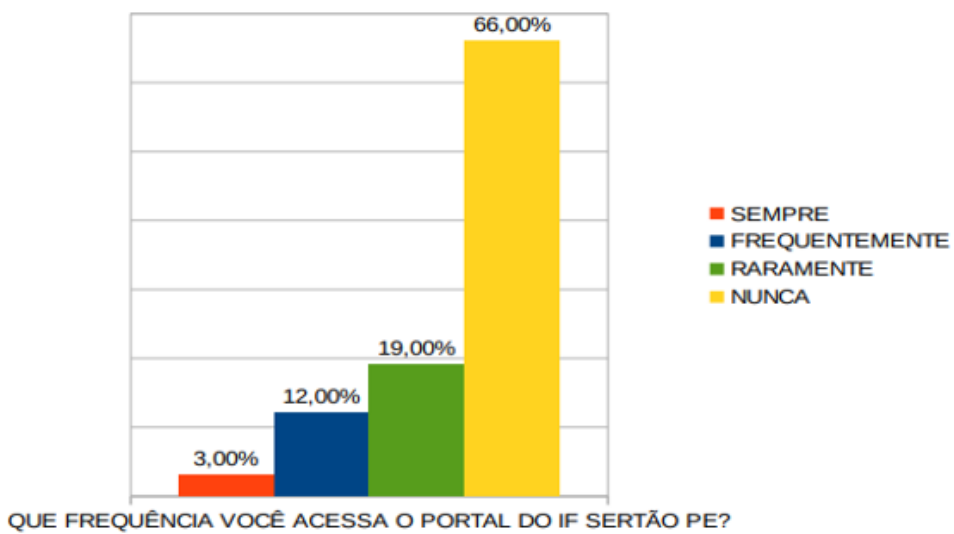

Fonte: Os autores (2018). 
Em relação à avaliação sobre o projeto, de modo geral, observa-se que o público-alvo julgou a relevância do desenvolvimento e a execução desse presente projeto na comunidade, atribuindo $73,37 \%$ como muito importante e $25,33 \%$ como importante (Gráfico 2).

Gráfico 2 - Avaliação da importância do projeto

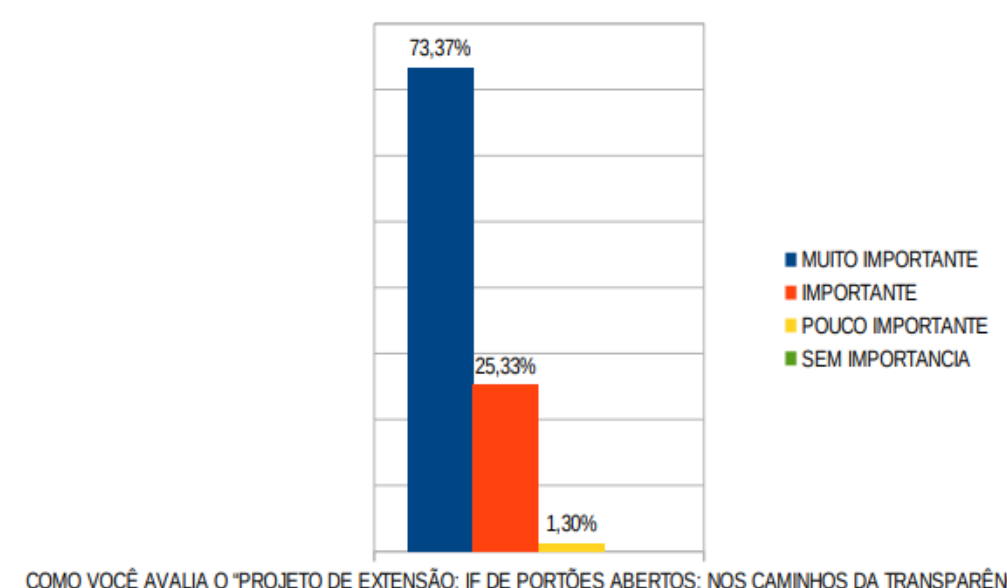

COMO VOCÊ AVALIA O "PROJETO DE EXTENSÃO: IF DE PORTÕES ABERTOS: NOS CAMINHOS DA TRANSPARÊNCIA"?

Fonte: Os autores (2018).

Analisando os dados, verificamos que a maioria dos estudantes pesquisados, $71 \%$, nunca tinha visitado as dependências do IF Sertão PE, assim como apenas 36\% tinham conhecimento dos cursos. Essas estatísticas reforçaram a ideia de efetivar uma visita ao Campus.

Após essa ida às escolas para falarmos das principais informações dispostas sobre o IF Sertão $\mathrm{PE}$, com ênfase nos programas e ações públicas que compõem o rol de transparência, sentimos a necessidade de levarmos o público-alvo (egressos de nível fundamental e médio) até o Instituto. A Figura 3 abaixo retrata a chegada dos estudantes ao Campus:

Figura 4 - Registro fotográfico dos estudantes na entrada principal do Campus

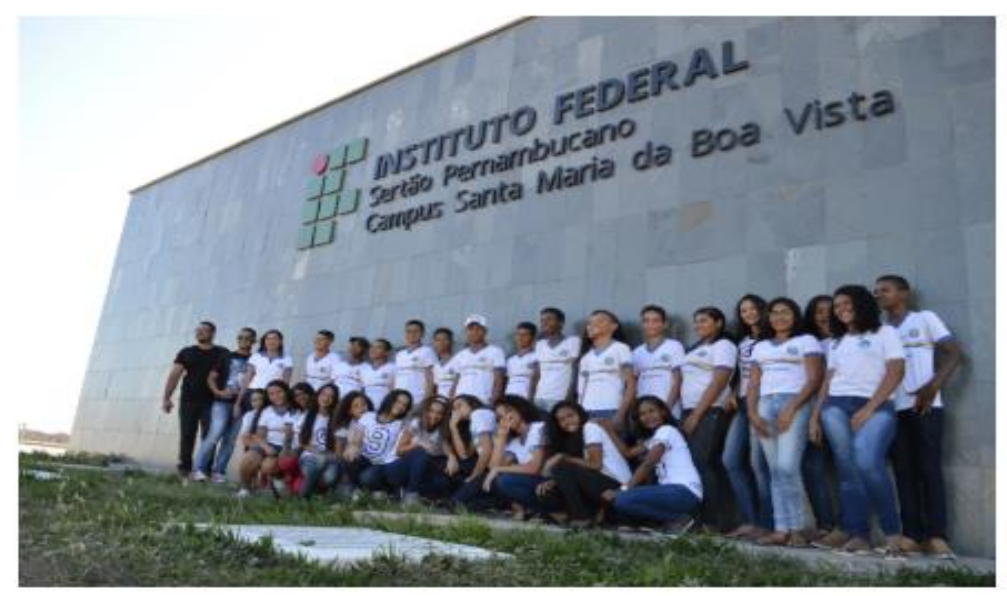

Fonte: Os autores (2018) 
Em uma das conversas com uma professora de uma escola foi destacada a importância das ações extensionistas, segundo a transcrição: “esse projeto é muito importante aqui para nós, estaremos sempre de portas abertas para ações como estas que nos trazem informações relevantes e também impacta na autoestima e motivação dos nossos alunos". Percebeu-se que o Instituto Federal pode ser uma oportunidade que os boavistanos e cidades circunvizinhas consideram como opção viável de acesso ao ensino técnico e tecnológico.

Uma das ações de extensão do projeto foi a realização de visitas técnicas guiadas demonstrando a infraestrutura física do Campus (salas de aula, laboratórios, auditórios, biblioteca, quadra poliesportiva e outros) a fim de criar vínculos, estimular a convivência e reforçar que a Instituição é um espaço público e social (Figura 4). Vale ressaltar, que a principal dificuldade encontrada nessa etapa foi o número reduzido de visitas devido ao ônibus da IF estar quebrado na época e a distância das escolas para a localização, sendo possível após a parceria entre as gestões institucionais do Campus e Município.

Figura 5 - Registro fotográfico da visita técnica guiada ao Campus

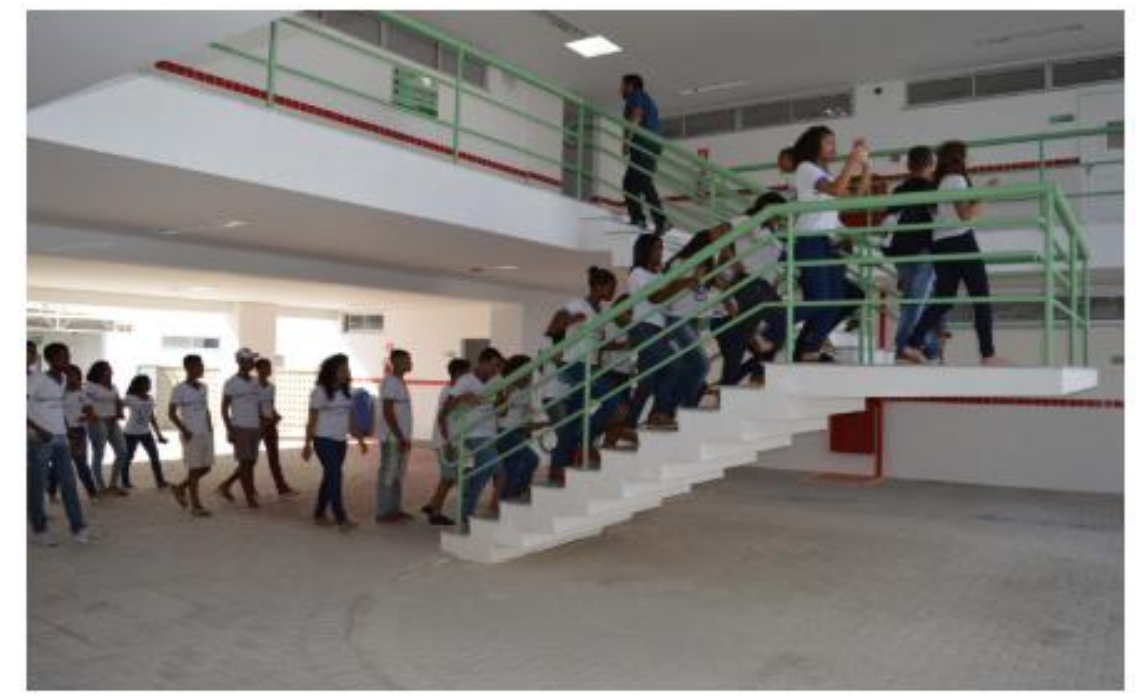

Fonte: Os autores (2018).

Destaca-se um dos relatos de estudante durante a visita "Colegas me disseram que é muito bom estudar no Instituto. Quero ingressar no IF Sertão-PE porque vejo oportunidades de crescimento e um bom futuro aqui”. Esse recorte demonstra que, mesmo com a demonstração das informações, o projeto de extensão perpassou aspectos de transparência pública, chegando a ser fator de incentivo a educação como pilar de transformação social. 


\section{CONSIDERAÇÕES FINAIS}

O relato objetivou descrever experiências quanto aos resultados de um projeto de extensão, com propósito de promover a transparência ativa do IF Sertão PE Campus Santa Maria da Boa Vista, demonstrando a relevância das informações públicas da Instituição para comunidade. Os resultados significativos foram ratificados pelo posicionamento positivo dos atores sociais quanto as ações de extensão desenvolvidas no projeto, conforme a avaliação aplicada.

Dentre as especificidades das ações extensionistas, apresentou-se o IF Sertão PE Campus Santa Maria da Boa Vista aos estudantes da rede pública de ensino, de modo global, a fim de demonstrar seu compromisso com a divulgação das informações. Assim, foi divulgado o balanço institucional das principais ações de ensino, pesquisa e extensão. Além disso, a realização das visitas guiadas ao Campus proporcionou a exposição da estrutura física e o funcionamento institucional.

É necessário informar que o desenvolvimento dessas atividades contribuiu para o exercício da cidadania por meio do controle social, promovendo também a troca de saberes entre os estudantes de ensino fundamental e médio do município de Santa Maria da Boa Vista e os alunos do Campus.

Considera-se que as ações elaboradas e executadas nesse projeto atingiram os objetivos propostos, embora não tenham exaurido o campo de possibilidades de atuação da Instituição enquanto agente transformadora da realidade local e promotora da transparência pública. Recomenda-se um estudo futuro para avaliar os impactos do IF no município, inclusive questionando a outros atores sociais, como a família, as organizações públicas e privadas e sociedade civil de modo geral.

\section{REFERÊNCIAS}

BRASIL. Lei $\mathrm{n}^{\circ} 12.527$, de 18 de novembro de 2011. Regula o acesso a informações previsto no inciso XXXIII do artigo $5^{\circ}$, no inciso II do $\& 3^{\circ}$ do art. 37 e no $\& 2^{\circ}$ do art. 216 da Constituição Federal; altera a Lei n.8.112, de 11 de dezembro de 1990; revoga a lei n.11.111, de 5 de maio de 2005, e dispositivos da Lei n. 8.159, de 8 de janeiro de 1991; e dá outras providências. Diário Oficial da União, Brasília, 19 nov. 2011.

BARTILOTTI, A. S. et al. Demandas repetitivas: litígios de uma insuficiência política. Interfaces: Revista de Extensão, Belo Horizonte, v. 3, n. 1, p. 111-116, jul./dez. 2015. 
CASTRO, D. P. Auditoria, contabilidade e controle interno no setor público. 5. ed. São Paulo: Atlas, 2013.

CRUZ, C. F. et al. Transparência da gestão pública municipal: um estudo a partir dos portais eletrônicos dos maiores municípios brasileiros. Revista de Administração Pública, Rio de Janeiro, v. 46, n. 1, p. 153-76, 2012.

FERNANDES, G. A. A. L.; FERNANDES, I. F. L. A.; TEIXEIRA, M. C. Estrutura de funcionamento e mecanismos de interação social nos tribunais de contas estaduais. Revista do Serviço Público, v. 69, p. 123-150, 14 dez. 2018. Doi: 10.21874/rsp.v69i0.3585.

INSTITUTO BRASILEIRO DE GEOGRAFIA E ESTATÍSTICA. Santa Maria da Boa

Vista. Disponível em: https://cidades.ibge.gov.br/brasil/pe/santa-maria-da-boavista/panorama. Acesso em: 20 jan. 2020.

IF SERTÃO PE. Campus Santa Maria da Boa Vista. Disponível em: http://www.ifsertaope.edu.br/index.php/san-o-campus. Acesso em: 18 maio 2020.

MIRANDA JÚNIOR, N. DA S.; PERMÍNIO, F. B.; LEITÃO, K. I. Extensão universitária na desmistificação do orçamento público: a experiência com a cidade estrutural -

DF. Participação, Brasília, n. 21, 2012.

PINHO, J. A. G.; SACRAMENTO, A. R. S. Accountability: já podemos traduzi-la para o português? Revista de Administração Pública, Rio de Janeiro, v. 43, n. 6, p. 1.3431.368, dez. 2009. Doi: 10.1590/S0034-76122009000600006.

VICCARI JR., A. et al. Lei de Responsabilidade Fiscal comentada: Lei Complementar n⿳亠 101, de 4 de maio de 2000. 6. ed. São Paulo: Atlas: 2009.

Submetido em 11 de julho de 2020.

Aprovado em 5 de outubro de 2020. 